\title{
BMJ Open Influence of premium versus value brand names on the smoking experience in a plain packaging environment: an experimental study
}

\author{
Gemma Skaczkowski, ${ }^{1}$ Sarah Durkin, ${ }^{1}$ Yoshihisa Kashima, ${ }^{2}$ Melanie Wakefield ${ }^{1}$
}

To cite: Skaczkowski G, Durkin S, Kashima Y, et al. Influence of premium versus value brand names on the smoking experience in a plain packaging environment: an experimental study. BMJ Open 2017;7:e014099. doi:10.1136/bmjopen-2016014099

- Prepublication history for this paper is available online. To view these files please visit the journal online (http://dx.doi.org/10.1136/ bmjopen-2016-014099).

Received 31 August 2016 Revised 30 October 2016 Accepted 7 December 2016

CrossMark

\section{${ }^{1}$ Centre for Behavioural Research in Cancer, Cancer Council Victoria, Melbourne, Victoria, Australia \\ ${ }^{2}$ School of Psychological Sciences, The University of Melbourne, Melbourne, Victoria, Australia}

\section{Correspondence to} Professor Melanie Wakefield; melanie.wakefield@cancervic. org.au

\section{ABSTRACT}

Objective: To examine the effect of branding, as indicated by brand name, on evaluation of the cigarette smoking experience.

Design: Between-subjects and within-subjects experimental study. Participants were randomly allocated to smoke a cigarette from a pack featuring a premium brand name and a cigarette from a pack featuring a value brand name. Within each condition, participants unknowingly smoked two identical cigarettes (either two premium or two value cigarettes). Setting: Australia, October 2014, 2 years after tobacco plain packaging implementation.

Participants: 81 current cigarette smokers aged $19-39$ years. From apparently premium and value brand-name packs, 40 smokers were allocated to smoke the same actual premium cigarettes and 41 were allocated to smoke the same actual value cigarettes.

Primary outcome measures: Experienced taste (flavour, satisfaction, enjoyment, quality, liking, mouthfeel and aftertaste), harshness, dryness, staleness, harm/strength measures (strength, tar, lightness, volume of smoke), draw effort and purchase intent.

Results: Cigarettes given a premium brand name were rated as having a better taste, were less harsh and less dry than identical cigarettes given a value brand name. This pattern was observed irrespective of whether the two packs actually contained premium or value cigarettes. These effects were specific: the brand name did not influence ratings of cigarette variant attributes (strength, tar, volume of smoke, lightness and draw effort).

Conclusions: Despite the belief that brand names represent genuine differences between cigarette products, the results suggest that at least some of this perceived sensory difference is attributable to brand image.

\section{INTRODUCTION}

The introduction of plain packaging in Australia removed all imagery, colours and symbols from cigarette packs, requiring all packs to be sold in drab dark brown

\section{Strengths and limitations of this study}

- This study is the first in a plain packaging environment to consider whether changing the apparent brand name of a cigarette influences the experience of smoking it.

- A within-subjects design was used, in which the same person smoked two cigarettes from different packs.

- Multiple premium/mainstream and value brands were used to enhance generalisability of findings.

- There is a need to establish the generalisability of the observed effect in different samples of smokers and different marketing and policy contexts, including in future years post-plain packaging when memories of pre-plain packaging brand imagery may have waned further.

packaging with standardised appearance and positioning of brand and variant names. ${ }^{1}$ There is increasing evidence from naturalistic and post-implementation studies that plain packaging negatively impacts the enjoyment, quality and satisfaction of cigarettes when they are smoked. ${ }^{2-6}$ This corroborates a large body of literature reporting that plain packaging significantly reduces the expected satisfaction, enjoyment and overall taste of a cigarette, as well as negatively influencing expectations about more targeted sensory attributes such as smoothness. ${ }^{7-12}$

By comparison, research on the effects of cigarette branding on cigarette taste in a plain packaging environment has been limited. In a plain packaging environment, brand names are one of the few remaining ways in which cigarette products can be distinguished and a means by which brands may retain their marketing sway. Qualitative research from the UK has indicated that some smokers believe they would not be affected by the change from a fully branded to a plain pack, because they would 
recognise that the cigarettes were the same by the brand name. ${ }^{13}$ In a recent online choice experiment, smoking and non-smoking Canadian females did not expect taste to differ between a female-oriented and a genderneutral brand. However, only two brand names were examined. Expectations of taste were shown to differ between cheaply and expensively priced packs (although prices in that study were not consistently presented with particular brand names). ${ }^{14}$

Brand names can evoke memories of past experience and brand image ${ }^{15} 16$ created through the repeated pairing of a name with particular symbols, attitudes and values when full branding was permitted. ${ }^{17}$ Therefore, brand image established prior to the introduction of plain packaging is likely to continue to influence smokers who can still recall the brand image of particular brands, even when the appearance of the pack has been standardised. Additionally, price is generally imputed to be an indicator of quality, ${ }^{18}$ with smokers found to distinguish brands in different market (price) segments in terms of the quality of the cigarette. ${ }^{15} 19$

In Australia, the cigarette market is generally categorised into premium, mainstream and value segments distinguished by price, ${ }^{20}$ although a super-value segment has emerged more recently due to the introduction of value brands in smaller pack sizes (20 cigarettes compared with typical value pack sizes of 35,40 and 50). ${ }^{21}$ Premium (and some of the more expensive mainstream) brands may, therefore, induce expectations of a better product than value brands. How much of the difference between these brands is a product of brand image, rather than genuine differences in the product, has not been examined in the peer-reviewed literature.

Two early research studies indicated that in the absence of brand information, smokers were unable to identify their own cigarette brand, ${ }^{22}{ }^{23}$ suggesting that branding plays an important role in establishing cigarette taste. However, the few other early studies that have examined this question found cigarettes to be distinguishable on the basis of taste alone. ${ }^{24-26}$ Only one study has examined whether changing the brand name of the same cigarette changes the smoking experience, finding that women rated a cigarette branded as 'April' as being more enjoyable, weaker, milder and as having better flavour, than when the same cigarette was branded as 'Frontiersman'. In comparison, men tended to prefer the 'Frontiersman' cigarette, though the effects were less pronounced. ${ }^{27}$

The wider consumer and sensory psychology literature indicates that branding can have a significant impact on sensory experience through a process called 'sensation transfer', in which the attributes conveyed by the brand are transferred to the product itself. ${ }^{28} \mathrm{~A}$ vast body of literature has shown sensation transfer effects for a wide range of consumable goods such as beer, ${ }^{29}$ fast food, ${ }^{30}$ pasta, ${ }^{31}$ cookies, ${ }^{32}$ soft drink ${ }^{33}$ and chocolate. ${ }^{34}$ Reviews of tobacco industry documents have shown the industry's use of this phenomenon to influence experienced taste through packaging. ${ }^{35} 36$ However, no peer-reviewed research has examined whether commercially available cigarette brands can induce a similar effect in the current consumer market.

The aim of the current study was to extend this sensory psychology literature into the tobacco control domain, by examining whether presenting the same cigarette as being a premium or a value brand changed smokers' experience of smoking the actual cigarette. Given the perceived association between price and cigarette quality, ${ }^{15}{ }^{19}$ it was hypothesised that cigarettes presented as premium brands would be rated more favourably (Hypothesis 1) and would have higher purchase likelihood (Hypothesis 2) than identical cigarettes presented as value brands. Additionally, this study did not vary the brand variant name. Therefore, it was hypothesised that attributes related to the brand variant, such as cigarette strength and tar level, ${ }^{37} 38$ would be unaffected by the change in brand name (Hypothesis $3)$. Finally, the influence of whether the cigarette actually contained within the two packs was itself a premium or value cigarette was examined (Research Question 1).

\section{METHOD \\ Design}

The study employed a between-subjects and withinsubjects design. Participants were first allocated to actually smoke one of two cigarette types, depending on the day of their testing session (smoke a premium cigarette or smoke a value cigarette). Within each condition, participants smoked that same cigarette type from two different packs. One pack displayed a premium brand name and the other displayed a value brand name. All packs were labelled with a brand variant that was equivalent to a mid-strength or 'Blue' variant. All participants were told that they would be participating in a cigarette taste test and were unaware that the two packs contained identical cigarettes.

After determination of whether a premium or value cigarette would be smoked, participants were allocated to one of nine possible brand pairings, leading to a total of 18 possible pairings (table 1). Packs within a pairing were matched for pack size as closely as possible. Participants were further randomly allocated to a pack order, which determined whether the cigarette from the premium or value pack was smoked first.

To ensure that the correct pack pairs and correct cigarettes were used, both packs within a pair displayed the same health warning. Each health warning was in circulation in Australia at the time of the study (see table 1). This aspect of the study was designed to reduce the potential for the health warning to independently influence evaluations.

\section{Choice of brands and brand variants}

Three premium/upper mainstream (more expensive) and three value (cheaper) mid-strength brand variants were used. To determine which brands to use in the 
Table 1 Brand pairs and health warnings for all packs

\begin{tabular}{|c|c|c|}
\hline Brand pair (pack size) & $\begin{array}{l}\text { Cigarette contained } \\
\text { in both packs }\end{array}$ & $\begin{array}{l}\text { Health warning } \\
\text { on both packs }\end{array}$ \\
\hline Testing days $1,2,7$ and 8 & Premium/upper mainstream & \\
\hline Winfield (20) + JPS (20) & Winfield & Child* \\
\hline Winfield (25) + Just Smokes (25) & Winfield & Child \\
\hline Winfield (25) + Choice (25) & Winfield & Child \\
\hline Peter Stuyvesant (20) + JPS (20) & Peter Stuyvesant & Toilet† \\
\hline Peter Stuyvesant (26) + Just Smokes (25) & Peter Stuyvesant & Toilet \\
\hline Peter Stuyvesant (26) + Choice(25) & Peter Stuyvesant & Toilet \\
\hline Peter Jackson (20) + JPS (20) & Peter Jackson & Heart muscleł \\
\hline Peter Jackson (30) + Just Smokes (30) & Peter Jackson & Heart muscle \\
\hline Peter Jackson (30) + Choice (25) & Peter Jackson & Heart muscle \\
\hline Testing days $3,4,5$ and 6 & Value & \\
\hline JPS (20) + Winfield (20) & JPS & Child \\
\hline JPS (20) + Peter Stuyvesant (20) & JPS & Child \\
\hline JPS (20) + Peter Jackson (20) & JPS & Child \\
\hline Just Smokes (25) + Winfield (25) & Just Smokes & Toilet \\
\hline Just Smokes (25) + Peter Stuyvesant (26) & Just Smokes & Toilet \\
\hline Just Smokes (30) + Peter Jackson (30) & Just Smokes & Toilet \\
\hline Choice (25) + Winfield (25) & Choice & Heart muscle \\
\hline Choice (25) + Peter Stuyvesant (26) & Choice & Heart muscle \\
\hline Choice (25) + Peter Jackson (30) & Choice & Heart muscle \\
\hline
\end{tabular}

main study, eight focus groups of smokers aged 1829 years were conducted, in which participants were asked to talk about their experience with different cigarette brands, brand variants and the attributes that differentiated them. An initial card-sort activity asked participants to sort different brands into groups, with no guidance on how they should sort them. Participants' groupings corresponded to the cost of brands (reflecting the premium, mainstream, value and super-value segments of the market) and this was perceived to be synonymous with perceptions of brand quality. Though there was variability in price within each grouping, brands in the premium or upper mainstream segments were consistently considered to be of higher quality than brands in the value segment.

Participants were then asked to sort a selection of common brand variants into a $3 \times 3$ table of cost (high, mid, low) by strength (high, mid, low). These focus groups allowed the identification of six relatively common brands with variants which were similarly midstrength but ranged from high to low cost for use in the main study. This study was based on a comparison of value brands (cheaper) to premium/upper mainstream brands (more expensive), all with mid-strength variants. For the sake of brevity, we refer to premium/upper mainstream brands as premium brands in the text. The recommended retail prices per cigarette stick at the time of the study for the chosen brand variants are shown in table 2, confirming the price disparity between the premium and value brand variants used.
Table 2 Recommended retail prices of the six eligible brand variants

\begin{tabular}{|c|c|c|c|}
\hline Brand & $\begin{array}{l}\text { Recommended } \\
\text { retail price per } \\
\text { pack }^{*}\end{array}$ & $\begin{array}{l}\text { Pack } \\
\text { size }\end{array}$ & $\begin{array}{l}\text { Price per } \\
\text { cigarette }\end{array}$ \\
\hline \multicolumn{4}{|c|}{ Premium/upper mainstream } \\
\hline $\begin{array}{l}\text { Peter Stuyvesant } \\
\text { Classic Blue }\end{array}$ & $\$ 19.95$ & 20 & $\$ 1.00$ \\
\hline Winfield Blue & $\$ 18.65$ & 20 & $\$ 0.93$ \\
\hline $\begin{array}{l}\text { Peter Jackson } \\
\text { Original Blue }\end{array}$ & $\$ 18.45$ & 20 & $\$ 0.92$ \\
\hline \multicolumn{4}{|l|}{ Value } \\
\hline $\begin{array}{l}\text { Choice Original } \\
\text { Blue }\end{array}$ & $\$ 20.70$ & 25 & $\$ 0.83$ \\
\hline Just Smokes Blue & $\$ 19.75$ & 25 & $\$ 0.79$ \\
\hline JPS Blue & $\$ 14.75$ & 20 & $\$ 0.74$ \\
\hline
\end{tabular}

Fieldwork for a pilot study was conducted in July 2014 and for the main study in October 2014.

\section{Participants and recruitment}

Smokers $(\mathrm{N}=90)$ were recruited through a professional recruitment agency from a pre-existing telephone panel of persons who had consented to be contacted about participating in research studies. Additional participants were recruited through snowball sampling. All potential participants were contacted via telephone and asked a series of screening questions. 
Participants were required to be 18-39 years old, currently smoke five or more cigarettes each day, primarily smoke factory-made cigarettes, not working in marketing, advertising, market research or the tobacco industry, be able to read and write English fluently and not have participated in a cigarette taste test/focus group discussion in the past 2 years. The Australian Government phased out tobacco advertising from the 1970s to the late 2000s,${ }^{39}$ meaning most of the smokers in the sample would have had at least some exposure to tobacco advertising during the vulnerable period of their early adolescence.

Additionally, participants were required to be familiar with the brand variants used in the study, since familiar consumers are generally more likely to experience sensation transfer and since brand familiarity has been shown to influence the effect of plain packaging on expected taste. ${ }^{40}{ }^{41}$ To establish familiarity, participants were asked whether they had smoked, more than once in the past, six different brand variants. Participants who nominated at least one of the eligible premium brand variants and at least one of the eligible value brand variants were deemed 'familiar'. Participants were allocated to a brand pairing on this basis. Where participants were 'familiar' with more than one brand pair, they were randomly allocated to a pairing.

Participants were asked to abstain from smoking for 1 hour prior to the session. Individual testing sessions were conducted in private outdoor areas in two Australian capital cities (Melbourne and Sydney). Where participants knew each other, their sessions were scheduled concurrently.

\section{Measures and procedure}

On arriving at the testing session, participants were provided with a summary of the study and were informed of the two apparent brand variants that they would be smoking during the session. Participants were asked to complete a computer-based questionnaire assessing their age, gender, education level, postcode (used to determine socioeconomic status using the Socio-economic Indexes for $\mathrm{Areas}^{42}$ ), time to first cigarette and number of daily cigarettes (used to calculate Heaviness of Smoking ${ }^{43}$ ), how many years they had been a daily smoker, readiness to quit (based on the trans-theoretical model's stage of change categories ${ }^{44}$ ), brand history and current level of craving.

Participants were then given their first allocated cigarette pack with the researcher reciting the brand variant name depicted on the pack. Participants were instructed to take out one cigarette, light it, take four puffs and then extinguish the cigarette in the ashtray provided. Participants were instructed that they would be asked to evaluate the cigarette strength, taste and how much they enjoyed it.

After smoking, participants were asked to rate the cigarette on 100-point Visual Analogue Scales (VAS) for the following sensory attributes, which were based on past research $^{8} 27$ and tobacco industry documents ${ }^{46} 47$ and were refined using information from the focus group discussions: 'Not enjoyable/Enjoyable', 'Low quality/ High quality', 'Not at all satisfying/Very satisfying', 'Bad flavour/Good flavour', 'Do not like at all/Like very much', 'Harsh/Smooth', 'Dry/Moist', 'Strong/Weak', 'Light/Heavy', 'Unpleasant aftertaste/Pleasant aftertaste', 'Bad mouthfeel/Good mouthfeel', 'Easy draw-effort/Hard draw-effort', 'Stale/Fresh', 'Low tar/ High tar' and 'Low volume of smoke/Full volume of smoke'. Participants were also asked to rate purchase intent on a 100-point VAS scale anchored at 'I would be very unlikely to buy these cigarettes/I would be very likely to buy these cigarettes'. The scales relating to harshness, staleness, dryness, strength and lightness were reverse coded.

After completing these ratings, participants took a 15 min break in which they were provided with unrelated reading material, water and crackers. After the break, participants were given the second cigarette which was again verbally identified by the brand variant on the pack.

After smoking and rating the second cigarette, participants completed some additional questions, including two prompted-recall questions asking them to identify which brands they had smoked during the session and in what order. Participants were also asked what they thought the study was about (open-ended) and who they thought was conducting it ('Government', 'A health research group', 'A tobacco company', 'A university research group', 'Don't know'). The final question asked to participants, "To what extent do you think you can tell the difference in taste between a cheap and an expensive cigarette brand?", with response options recorded on a seven-point scale, anchored at 'Definitely cannot' and 'Definitely can' with a mid-point of 'Not sure'.

Participants were then debriefed and provided with a disclosure statement and Quit brochure, if they wished to take one. Participants were offered AUD $\$ 80$ reimbursement for their time. During the session, research assistants recorded how many puffs the participant took of each cigarette. Where the research assistant was unable to view the respondent $(n=3)$, it was assumed that they had taken four puffs, as instructed.

\section{Data analysis}

Analyses were conducted in SPSS V.20. Eight participants did not correctly recall the brand names on the packs that they had been given to smoke during the session. Since knowledge of the brand name was crucial to the success of the manipulation, these participants were excluded from the analyses. Additionally, one participant indicated at the end of the session that he had misunderstood how to answer the VAS scales and was therefore excluded. This left a final sample of 81 participants.

A principal components analysis using an oblique rotation was conducted on the 15 sensory measures from 
both the premium and value brand-segment conditions. First, ratings within each condition were standardised. Next, the standardised ratings from both premium and value brands were combined to form a single variable for each sensory characteristic. Correlations between the ratings were examined and 'draw effort' was excluded as it did not correlate with any other item above 0.30. Eigenvalues, scree plots and component loadings indicated a three-factor solution. Items were attributed to a factor where they loaded $>0.40$. Cigarette 'Taste' consisted of satisfaction, enjoyment, quality, liking, mouthfeel, flavour and aftertaste (Cronbach's $\alpha=0.92$ ). A Taste score was computed for the premium brand-segment condition by summing and averaging the relevant unstandardised items within that condition. This process was repeated for the value brand-segment condition.

The second factor included items generally thought to represent the concept of strength/harm, and which are often associated by smokers with the cigarette 'variant' (tar, volume, lightness (reverse coded), strength). The strength variable cross-loaded on two factors $>0.40$; however, the measure was correlated only with lightness and volume $>0.30$ and was therefore included with the 'variant' factor. The items of harshness, dryness and staleness loaded on a third 'sensory' factor. However, both scales did not show acceptable internal reliability (Cronbach's $\alpha$ 's $<0.70$ ). Therefore, the individual items for each of these factors were analysed separately but considered alongside each other as separate indicators of the 'variant' and 'sensory' factors in the results.

Analyses are reported (1) unadjusted and (2) adjusted for pack order and the difference in the number of puffs between the apparent premium and value brand. Preliminary analyses examined whether ratings of the actual premium and value cigarettes differed irrespective of the apparent brand name that a cigarette was given. To do this, the ratings of the actual cigarettes were averaged over the brand-segment conditions (ie, ratings of a premium cigarette smoked from a premium and a value pack were averaged). One-way analysis of variance (ANOVA) tests compared ratings of participants who received an actual premium cigarette to smoke (from both packs) and those who received an actual value cigarette to smoke (from both packs). In other words, ignoring the brand name that the cigarettes were given, actual premium cigarettes were compared with actual value cigarettes.

For the main hypotheses, repeated measures ANOVAs compared the composite Taste scores and the remaining individual 'sensory' and 'variant' items from the premium and value brand-segment conditions. To evaluate whether the same results were observed for the groups of participants who actually smoked the premium or the value cigarette of the pair, a secondary analysis of the adjusted model included the actual cigarette smoked (premium/value) as a between-subjects factor.

A sensitivity analysis was conducted controlling for the apparent specific premium and value brands (eg, JPS,
Winfield) to which participants were allocated. The analysis revealed the same pattern as that reported overall. Another sensitivity analysis included health warning as a between-subjects factor. The analysis revealed no interaction between the health warning and the brandsegment condition (premium/value) for any outcome ( $p$ 's $>0.05$ ), indicating no significant influence of health warning allocation.

\section{RESULTS}

\section{Sample characteristics}

Table 3 shows the demographic characteristics of participants. In the final sample of 81 participants, 40 were allocated to smoke the actual premium cigarette and 41 were allocated to smoke the actual value cigarette from the two packs.

The majority of participants $(84 \%)$ scored 5 or above on the seven-point scale assessing to what extent participants believed that they would be able to tell the difference between an expensive and a cheap brand of cigarette, indicating that most were confident they could tell the difference. Most participants (67.9\%) thought the study was being conducted on behalf of a tobacco company. None thought the study was assessing two identical cigarettes under different brand names, indicating that the cover story of a cigarette taste test was believable.

Table 3 Demographic characteristics of the sample

\begin{tabular}{ll}
\hline & Per cent \\
\hline $\begin{array}{l}\text { Gender } \\
\text { Male }\end{array}$ & 55.6 \\
$\quad$ Female & 44.4 \\
Education & \\
$\quad$ Up to year 12 & 30.9 \\
$\quad$ Tertiary education and above & 69.1 \\
Socioeconomic status* & \\
$\quad$ Low & 34.2 \\
Mid & 44.3 \\
$\quad$ High & 21.5 \\
Number of years smoking & 35.8 \\
$\quad \leq 5$ & 64.2 \\
$\quad \geq 6$ & 28.4 \\
Readiness to quit & 71.6 \\
$\quad$ Contemplators/preparers & Mean (SD) \\
Precontemplators & $28.41(6.43)$ \\
$\quad$ Age & $2.20(1.35)$ \\
Heaviness of smoking $\dagger$ & $3.65(1.25)$ \\
Level of craving & \\
\hline
\end{tabular}

${ }^{*} n=79$ due to missing data on this variable.

†Three participants responded 'don't know' to the question assessing time to first cigarette. As this variable is combined with the number of daily cigarettes category-level variable to calculate $\mathrm{HSI}$, the category for number of daily cigarettes was imputed for the time to first cigarette score.

łResponse options were 1 'Not at all', 2 'Hardly at all', 3 'A little', 4 'Somewhat', 5 'Quite a bit', 6 'A great deal' and 'Don't know/can't say'. 


\section{Preliminary analyses}

Examination of differences between the actual premium and value cigarettes

As shown in table 4, ignoring the apparent brand name given to the cigarette, premium and value cigarettes actually did not differ on any of the Taste, sensory or variant measures, or on draw effort or purchase intent.

\section{Main analyses}

Hypotheses 1 and 2: effect of brand name on Taste, sensory measures and purchase intent

Cigarettes smoked from packs displaying premium brand names were rated as having better Taste, being less harsh and less dry than identical cigarettes smoked from packs displaying value brand names (table 5). There was no effect of brand-segment condition on ratings of cigarette staleness. While cigarettes smoked from a premium pack tended towards higher purchase likelihood than cigarettes smoked from a value pack, this difference was not significant (see table 5).

Hypothesis 3: effect of brand name on variant measures and draw effort

As seen in table 5, there was no effect of brand-segment condition on ratings of tar, strength, volume of smoke, lightness or draw effort.
Research question 1: effect of the actual cigarette contained in the packs

When the actual cigarette smoked (premium/value) was entered into each model, the interaction between brandsegment condition and the actual cigarette smoked was not significant for Taste $\left(\mathrm{F}(1,77)=0.10, \mathrm{p}=0.748, \eta_{\mathrm{p}}^{2}=0.00\right)$, any of the sensory measures (harshness $(\mathrm{F}(1,77)=1.40$, $\left.\mathrm{p}=0.241, \quad \eta_{\mathrm{p}}^{2}=0.02\right)$, dryness $\quad(\mathrm{F}(1,77)=0.00, \quad \mathrm{p}=0.971$, $\left.\eta_{\mathrm{p}}^{2}=0.00\right)$, staleness $\left.\left(\mathrm{F}(1,77)=0.20, \mathrm{p}=0.658, \eta_{\mathrm{p}}^{2}=0.00\right)\right)$, any of the variant measures $(\operatorname{tar}(\mathrm{F}(1,77)=1.29, \mathrm{p}=0.259$, $\left.\eta_{\mathrm{p}}^{2}=0.02\right)$, strength $\quad\left(\mathrm{F}(1,77)=1.97, \quad \mathrm{p}=0.164, \quad \eta_{\mathrm{p}}^{2}=0.03\right)$, volume $\quad\left(\mathrm{F}(1,77)=0.00, \quad \mathrm{p}=0.951, \quad \eta_{\mathrm{p}}^{2}=0.00\right)$, lightness $\left.\left(\mathrm{F}(1,77)=1.95, \mathrm{p}=0.167, \eta_{\mathrm{p}}^{2}=0.03\right)\right)$, nor for draw effort $(\mathrm{F}$ $\left.(1,77)=0.16, \quad \mathrm{p}=0.695, \quad \eta_{\mathrm{p}}^{2}=0.00\right)$, or purchase intent $\left(\mathrm{F}(1,77)=0.01, \mathrm{p}=0.942, \eta_{\mathrm{p}}^{2}=0.00\right)$. This indicates that those who received an actual premium cigarette to smoke showed the same pattern of results as those given an actual value cigarette to smoke.

\section{DISCUSSION}

The majority of smokers in this study believed that they would be able to tell the difference between a cheap and an expensive brand of cigarette. However, the results suggest that experienced differences between these products are, at least in part, a product of brand image. When the results were averaged across apparent

Table 4 Difference between ratings of actual premium and value cigarettes on Taste, sensory or variant measures, draw effort and purchase intent when the brand name on the pack is ignored

\begin{tabular}{|c|c|c|c|c|}
\hline Rating* $^{*}$ & $\begin{array}{l}\text { Actual premium } \\
\text { cigarette }(n=40) \\
\text { (mean }(S E)) \dagger\end{array}$ & $\begin{array}{l}\text { Actual value } \\
\text { cigarette }(n=41) \\
(\text { mean }(S E)) \dagger\end{array}$ & Unadjusted model & Adjusted modelł \\
\hline Taste (bad-good) & $55.99(2.23)$ & $60.33(2.20)$ & $\begin{array}{l}F(1,79)=2.32, p=0.132 \\
\eta_{p}^{2}=0.03\end{array}$ & $\begin{array}{l}F(1,77)=1.91, p=0.171, \\
\eta_{p}^{2}=0.02\end{array}$ \\
\hline \multicolumn{5}{|l|}{ Sensory measures } \\
\hline Harshness (smooth—harsh) & $52.60(3.46)$ & $47.42(3.40)$ & $\begin{array}{l}F(1,79)=1.48, p=0.227 \\
\eta_{p}^{2}=0.02\end{array}$ & $\begin{array}{l}F(1,77)=1.13, p=0.291, \\
\eta_{p}^{2}=0.01\end{array}$ \\
\hline Dryness (moist-dry) & $56.29(2.58)$ & $59.30(2.54)$ & $\begin{array}{l}F(1,79)=1.04, p=0.310 \\
\eta_{p}^{2}=0.01\end{array}$ & $\begin{array}{l}F(1,77)=0.68, p=0.411, \\
\eta_{p}^{2}=0.01\end{array}$ \\
\hline Staleness (fresh-stale) & 47.91 (3.29) & $49.54(3.24)$ & $\begin{array}{l}F(1,79)=0.16, p=0.688 \\
\eta_{p}^{2}=0.00\end{array}$ & $\begin{array}{l}F(1,77)=0.12, p=0.726, \\
\eta_{p}^{2}=0.00\end{array}$ \\
\hline \multicolumn{5}{|l|}{ Variant measures } \\
\hline Tar (low—high) & $51.87(2.07)$ & $47.56(2.04)$ & $\begin{array}{l}F(1,79)=1.71, p=0.194 \\
\eta_{p}^{2}=0.02\end{array}$ & $\begin{array}{l}F(1,77)=2.18, p=0.144, \\
\eta_{p}^{2}=0.03\end{array}$ \\
\hline Strength (weak—strong) & $53.75(2.48)$ & $57.14(2.44)$ & $\begin{array}{l}F(1,79)=1.19, p=0.278 \\
\eta_{p}^{2}=0.02\end{array}$ & $\begin{array}{l}F(1,77)=0.94, p=0.335, \\
\eta_{p}^{2}=0.01\end{array}$ \\
\hline Volume (low-full) & $53.72(2.62)$ & $52.52(2.57)$ & $\begin{array}{l}F(1,79)=0.01, p=0.939 \\
\eta_{p}^{2}=0.00\end{array}$ & $\begin{array}{l}F(1,77)=0.11, p=0.745, \\
\eta_{p}^{2}=0.00\end{array}$ \\
\hline Lightness (heavy—light) & $46.10(2.57)$ & $50.17(2.53)$ & $\begin{array}{l}F(1,79)=1.20, p=0.277 \\
\eta_{p}^{2}=0.02\end{array}$ & $\begin{array}{l}F(1,77)=1.26, p=0.265, \\
\eta_{p}^{2}=0.02\end{array}$ \\
\hline Draw effort (easy—hard) & $43.32(3.04)$ & $40.50(2.99)$ & $\begin{array}{l}F(1,79)=0.42, p=0.520 \\
\eta_{p}^{2}=0.01\end{array}$ & $\begin{array}{l}F(1,77)=0.43, p=0.513, \\
\eta_{p}^{2}=0.01\end{array}$ \\
\hline Purchase intent (unlikely_likely) & $52.76(3.35)$ & $59.51(3.30)$ & $\begin{array}{l}F(1,79)=2.63, p=0.109 \\
\eta_{p}^{2}=0.03\end{array}$ & $\begin{array}{l}F(1,77)=2.05, p=0.157, \\
\eta_{p}^{2}=0.03\end{array}$ \\
\hline
\end{tabular}


Table 5 Effect of apparent brand name on Taste, sensory or variant measures, draw effort and purchase intent

\begin{tabular}{|c|c|c|c|c|}
\hline & \multicolumn{4}{|c|}{ Brand name displayed on pack ${ }^{*}$} \\
\hline & $\begin{array}{l}\text { Premium } \\
\text { (mean (SE)) }\end{array}$ & $\begin{array}{l}\text { Value } \\
\text { (mean (SE)) }\end{array}$ & Unadjusted model & Adjusted model† \\
\hline Taste (bad-good) & $61.92(2.32)$ & $54.47(2.14)$ & $F(1,80)=5.70, p=0.019, \eta_{p}^{2}=0.07$ & $F(1,78)=5.51, p=0.021, \eta_{p}^{2}=0.07$ \\
\hline \multicolumn{5}{|l|}{ Sensory measures } \\
\hline $\begin{array}{l}\text { Harshness } \\
\text { (smooth-harsh) }\end{array}$ & $45.13(3.19)$ & $54.80(2.87)$ & $F(1,80)=7.22, p=0.009, \eta_{p}^{2}=0.08$ & $F(1,78)=6.98, p=0.010, \eta_{p}^{2}=0.08$ \\
\hline Dryness (moist-dry) & $53.57(2.49)$ & $62.06(2.26)$ & $F(1,80)=7.31, p=0.008, \eta_{p}^{2}=0.08$ & $F(1,78)=7.46, p=0.008, \eta_{p}^{2}=0.09$ \\
\hline Staleness (fresh-stale) & 49.99 (3.22) & $47.47(2.82)$ & $F(1,80)=0.36, p=0.550, \eta_{p}^{2}=0.00$ & $F(1,78)=0.40, p=0.528, \eta_{p}^{2}=0.01$ \\
\hline \multicolumn{5}{|l|}{ Variant measures } \\
\hline Tar (low-high) & $48.92(2.03)$ & $50.44(2.00)$ & $F(1,80)=0.33, p=0.567, \eta_{p}^{2}=0.00$ & $F(1,78)=0.31, p=0.577, \eta_{p}^{2}=0.00$ \\
\hline Strength (weak-strong) & $54.65(2.52)$ & $56.30(2.09)$ & $F(1,80)=0.37, p=0.545, \eta_{p}^{2}=0.01$ & $F(1,78)=0.29, p=0.593, \eta_{p}^{2}=0.00$ \\
\hline Volume (low-full) & $52.83(2.52)$ & $53.40(2.51)$ & $F(1,80)=0.05, p=0.825, \eta_{p}^{2}=0.00$ & $F(1,78)=0.03, p=0.871, \eta_{p}^{2}=0.00$ \\
\hline Lightness (heavy-light) & $49.06(2.58)$ & $47.27(2.09)$ & $F(1,80)=0.43, p=0.512, \eta_{p}^{2}=0.01$ & $F(1,78)=0.36, p=0.553, \eta_{p}^{2}=0.01$ \\
\hline Draw effort (easy-hard) & $41.34(2.80)$ & $42.44(2.95)$ & $F(1,80)=0.10, p=0.758, \eta_{p}^{2}=0.00$ & $F(1,78)=0.08, p=0.778, \eta_{p}^{2}=0.00$ \\
\hline $\begin{array}{l}\text { Purchase intent } \\
\text { (unlikely-likely) }\end{array}$ & $59.61(3.34)$ & $52.77(3.19)$ & $F(1,80)=2.47, p=0.120, \eta_{p}^{2}=0.03$ & $F(1,78)=2.29, p=0.134, \eta_{p}^{2}=0.03$ \\
\hline
\end{tabular}

${ }^{*}$ Estimates are taken from the adjusted model.

†Analyses controlled for pack order and the difference in number of puffs between the premium and value pack.

brand-segment conditions, the perceived taste of actual premium and value cigarettes did not differ. However, when either cigarette was presented as being a premium brand, it was rated as having better overall taste, and as less harsh and dry than an identical cigarette presented as a value brand, supporting Hypothesis 1 . This pattern was the same irrespective of the type of cigarette actually smoked. These findings are consistent with past research showing that other elements of packaging and branding can significantly alter smokers' experiences ${ }^{2-5} 27$ providing evidence for sensation transfer in the tobacco domain.

As hypothesised, the brand-segment name manipulation changed how the cigarette was experienced along a number of attributes, including overall taste and specific sensory outcomes of harshness and dryness. The manipulation had no effect on perceptions of staleness, though it is possible that this attribute was perceived as being related more to the presentation method than to the brand name, given both cigarettes were presented in already-opened packs.

The brand-segment manipulation did not influence perceptions of cigarette strength, lightness, volume of smoke or tar level, supporting Hypothesis 3. Though these factors did not form a reliable factor, they were related to one another and may be generally thought to represent the concept of harm, which is often associated by smokers with the cigarette variant. As all variant names used were the 'Blue' equivalent of each brand, these findings provide some support for the hypothesis that the manipulation would have no impact on attributes related to the variant name. Further research is needed to illuminate the role of variant names in the perceived smoking experience. Plain packaging legislation in Australia did not restrict the breadth of brand and variant names and since its introduction variant names for some brands have become more descriptive. ${ }^{48}$ For instance, Pall Mall Amber and Pall Mall Blue were renamed Pall Mall Smooth Amber and Pall Mall Rich Blue, respectively. ${ }^{48}$ Whether the evocative language that has emerged in these variant names improves the subjective smoking experience is an important question for future research. Indeed, research has already identified that variant descriptors on standardised packs influence expected hedonic and sensory attributes, including appeal, strength, tar level and quality. ${ }^{37}{ }^{49}$ Restrictions on variant names have already been implemented in Uruguay, which has limited each brand to a single variant. ${ }^{50}$ Further regulation and restriction of brand and variant names could also be considered in Australia, thereby removing one of the last remaining means through which tobacco companies may promote and distinguish their products. ${ }^{5152}$

Although outside conventional statistical significance, the pattern of results tended to show that smokers had higher purchase intent for the cigarettes that they smoked from the premium pack compared with the value pack. This provides only limited support for Hypothesis 2. Purchase intent is likely to be influenced by other unmeasured factors such as one's ability to purchase cigarettes at a particular price point or a current strong preference for a brand different from that tested in the study.

Replication of these results is needed with different brand pairs and brand variants, and with larger sample sizes to examine variation in the strength of effect for different brand pairs and brand variants. Nevertheless, the results are consistent with a large body of literature on sensation transfer indicating that the experience of smoking a cigarette, like other consumable goods, is open to manipulation by extrinsic information. The only published study to have previously examined the 
influence of brand names on the cigarette experience used fake brand names with strong gender connotations. ${ }^{27}$ To the best of our knowledge, the current study is the first to demonstrate this effect using commercially available cigarette brands. Additionally, the within-subjects design of this study shows that the brand name can influence perception even when two identical cigarettes are smoked within a short timeframe by the same person.

\section{Strengths and limitations}

The introduction of tobacco plain packaging legislation has provided a unique environment in which to evaluate the persistent effect of branding through brand name on the smoking experience. Past studies occurred using fully branded packs and cigarette sticks and so needed to obscure markings on the cigarette stick which might identify the brand, either by blindfolding participants ${ }^{22}$ or by covering the cigarette rod with a label, ${ }^{24}$ either of which could themselves influence taste ratings. Under the Tobacco Plain Packaging Act 2011, ${ }^{53}$ the appearance of cigarette sticks has been standardised to a white paper casing or white with a cork tip and with brand names and decorative features removed from the stick. ${ }^{1}$ This created a unique opportunity to use unmodified, commercially available products. Cigarette sticks can only display a small alphanumeric code of standardised appearance and position. ${ }^{1}$ Although it is possible that some smokers may have noticed that the codes on both cigarettes were the same, no participant identified this when asked what the study was about.

To ensure that participants were able to smoke both cigarettes within the session time, only a limited amount of each cigarette was smoked. Although focus groups conducted in preparation for this study found that smokers considered four puffs sufficient to evaluate cigarette taste, a different result may be observed where smokers are able to experience the entire cigarette in a more realistic smoking environment. Studies of plain packaging using naturalistic study designs, in which participants are given test packs to use in their own time, have found that the negative impact of plain packaging is observed even when participants transfer their own cigarettes/tobacco to the plain packs. ${ }^{4-6}$ This suggests that the effect of extrinsic information may override objective sensory properties even when participants are aware of the manipulation.

Fieldwork for the study was conducted in late 2014, just 2 years after implementation of tobacco plain packaging in Australia, so brand names are likely to still be heavily imbued with most of the brand imagery developed over decades of full branding and marketing. Even where tobacco advertising and promotion has been banned, previously constructed brand images may persist, particularly where foreign tobacco advertising and sponsorship is still allowed. ${ }^{19} 54$

Consistent with this, our study found the experience of smoking cigarettes to be significantly influenced by the apparent brand name. Research may elicit different findings among smokers studied many years after plain packaging implementation where memories of brand imagery may have had more time to decay.

A limitation of this study was the small sample size and in particular, the relatively small proportion $(28.4 \%)$ of participants seriously considering quitting in the next 6 months, given Brennan et $a l^{55}$ identified $36.5 \%$ of Australian smokers in a national sample to be intending to quit in the next month. This may be due to the nature of the study, which was a cigarette taste test perceived as most likely undertaken by a tobacco company, thereby potentially being more attractive to those who wish to continue smoking. It is also possible that the online panel used to recruit participants was not representative of the broader smoker population. Further research with different samples of participants, including among smokers who regularly smoke particular brands and variants, would help to establish the generalisability of these results.

\section{CONCLUSIONS AND IMPLICATIONS}

Even before the introduction of plain packaging in 2012, Australia had one of the world's darkest markets, in which most forms of tobacco advertising and promotion were banned. ${ }^{56}$ Our findings indicate that even where all other forms of brand communication have been removed and the pack itself has been standardised, smokers' experiences may still be manipulated by the persistent marketing influence of the brand name.

In qualitative interviews evaluating a simulation of plain packaging in a naturalistic context in the UK, participants described an attachment to the product itself, rather than to the packaging that it comes in. ${ }^{57}$ However, the results of the current study provide preliminary evidence that the product smokers think they are consuming may have more to do with brand image, and less to do with the actual product, than they realise. Research on plain packaging has shown that smokers who experienced more concern than enjoyment from their smoking were more likely to intend to quit in the next month. ${ }^{55}$ Correcting smokers' misperceptions that particular brands taste any better than others through concerted educational and other interventions may weaken the attachment that smokers feel towards 'their' brand and reduce the perceived and experienced palatability of cigarettes. Though the brand image built in the pre-plain packaging era will likely take many years or even decades to wane, policy restrictions could target any further attempts to reinforce quality differences between brands and brand-segments. For instance, cigarette pricing or the use of price boards to give prominence to particular brands can be effective promotional strategies in a dark market. ${ }^{58-60}$ Limiting the display of price boards or standardising the price per cigarette stick may also limit perceived differences between market segments. 
Contributors MW, SD and GS conceived the study. MW, SD and GS designed the survey questions and study protocol. GS coordinated fieldwork and undertook data analysis, and SD and YK supervised these study phases. GS drafted the manuscript and MW, SD and YK revised the content. All authors approved the final submitted version.

Funding This work was supported by Australian National Health and Medical Research Council (NHMRC) grant number 623203. GS was supported by an Australian Postgraduate Award. MW is supported by an Australian National Health and Medical Research Council Principal Research Fellowship.

Competing interests None declared.

Ethics approval Ethical approval for the study was provided by the Human Research Ethics Committee of Cancer Council Victoria.

Provenance and peer review Not commissioned; externally peer reviewed.

Data sharing statement No additional data are available.

Open Access This is an Open Access article distributed in accordance with the Creative Commons Attribution Non Commercial (CC BY-NC 4.0) license, which permits others to distribute, remix, adapt, build upon this work noncommercially, and license their derivative works on different terms, provided the original work is properly cited and the use is non-commercial. See: http:// creativecommons.org/licenses/by-nc/4.0/

\section{REFERENCES}

1. Scollo M, Lindorff $\mathrm{K}$, Coomber $\mathrm{K}$, et al. Standardised packaging and new enlarged graphic health warnings for tobacco products in Australia-legislative requirements and implementation of the Tobacco Plain Packaging Act 2011 and the Competition and Consumer (Tobacco) Information Standard, 2011. Tob Control 2015;24:ii9-16.

2. Wakefield M, Coomber K, Zacher M, et al. Australian adult smokers' responses to plain packaging with larger graphic health warnings 1 year after implementation: results from a national cross-sectional tracking survey. Tob Control 2015;24:ii17-25.

3. Wakefield M, Hayes L, Durkin S, et al. Introduction effects of the Australian plain packaging policy on adult smokers: a cross-sectional study. BMJ Open 2013;3:e003175.

4. Moodie C, Mackintosh AM. Young adult women smokers' response to using plain cigarette packaging: a naturalistic approach. BMJ Open 2013;3:e002402.

5. Moodie C, Mackintosh AM, Hastings G, et al. Young adult smokers' perceptions of plain packaging: a pilot naturalistic study. Tob Control 2011;20:367-73.

6. Gallopel-Morvan K, Moodie C, Eker F, et al. Perceptions of plain packaging among young adult roll-your-own smokers in France: a naturalistic approach. Tob Control 2015;24:e39-44.

7. White CM, Hammond D, Thrasher JF, et al. The potential impact of plain packaging of cigarette products among Brazilian young women: an experimental study. BMC Public Health 2012;12:737-46.

8. Wakefield M, Germain D, Durkin S. How does increasingly plainer cigarette packaging influence adult smokers' perceptions about brand image? An experimental study. Tob Control 2008;17:416-21.

9. Wakefield M, Germain D, Durkin S, et al. Do larger pictorial health warnings diminish the need for plain packaging of cigarettes? Addiction 2012;107:1159-67.

10. Doxey J, Hammond D. Deadly in pink: the impact of cigarette packaging among young women. Tob Control 2011;20:353-60.

11. Hammond D, White C, Anderson W, et al. The perceptions of UK youth of branded and standardized, 'plain' cigarette packaging. Eur J Public Health 2014;24:537-43.

12. Guillaumier A, Bonevski B, Paul C, et al. Socioeconomically disadvantaged smokers' ratings of plain and branded cigarette packaging: an experimental study. BMJ Open 2014:4:e004078.

13. Moodie C, Purves R, Mckell J, et al. Young women smokers' perceptions and use of counterfeit cigarettes: would plain packaging make a difference? Addict Res Theory 2014;22:263-70.

14. Kotnowski K, Fong GT, Gallopel-Morvan K, et al. The impact of cigarette packaging design among young females in Canada: findings from a discrete choice experiment. Nicotine Tob Res 2016;18:1348-56.

15. Carter SM. The Australian cigarette brand as product, person, and symbol. Tob Control 2003;12:iii79-86.

16. Hoek J, Gendall P, Gifford H, et al. Tobacco branding, plain packaging, pictorial warnings, and symbolic consumption. Qual Health Res 2012;22:630-9.
17. Nord WR, Peter JP. A behavior modification perspective on marketing. J Mark 1980;44:36-47.

18. Rao AR. The quality of price as a quality cue. J Mark Res 2005;42:401-5.

19. Gfk bluemoon. Market research to determine effective plain packaging of tobacco products. Canberra: Department of Health and Ageing, 2011.

20. Retail World annual report 2013. Market sizes and shares. Retail World 2013; December: 30

21. Scollo M, Zacher M, Coomber K, et al. Changes in use of types of tobacco products by pack sizes and price segments, prices paid and consumption following the introduction of plain packaging in Australia. Tob Control 2015;24:ii66-75.

22. Husband RW, Godfrey J. An experimental study of cigarette identification. J Appl Psychol 1934;18:220-3.

23. Jaffe AJ, Glaros AG. Taste dimensions in cigarette discrimination: a multidimensional scaling approach. Addict Behav 1986;11: 407-13.

24. Littman RA, Manning HM. A methodological study of cigarette brand discrimination. J Appl Psychol 1954;38:185-90.

25. Prothro ET. Identification of American, British, and Lebanese cigarettes. J Appl Psychol 1953;37:54-6.

26. Ramond CK, Rachal LH, Marks MR. Brand discrimination among cigarette smokers. J Appl Psychol 1950;34:282-4.

27. Friedman HH, Dipple WS. The effect of masculine and feminine brand names on the perceived taste of a cigarette. Decis Sci 1978;9:467-71.

28. Cheskin L. How to predict what people will buy. New York: Liveright Publishing Corporation, 1957.

29. Allison RI, Uhl KP. Influence of beer brand identification on taste perception. J Mark Res 1964:1:36-9.

30. Robinson TN, Borzekowski DLG, Matheson DM, et al. Effects of fast food branding on young children's taste preferences. Arch Pediatr Adolesc Med 2007:161:792-7.

31. Di Monaco R, Cavella S, Di Marzo S, et al. The effect of expectations generated by brand name on the acceptability of dried semolina pasta. Food Qual Prefer 2004;15: 429-37.

32. Cavanagh KV, Forestell CA. The effect of brand names on flavor perception and consumption in restrained and unrestrained eaters. Food Qual Prefer 2013;28:505-9.

33. Pierce WD. Which Coke is it? Social influence in the marketplace. Psychol Rep 1987;60:279-86.

34. Bonham P, Greenlee D, Herbert CS, et al. Knowledge of brand and preference. Psychol Rep 1995;76:1297-8.

35. Wakefield M, Morley C, Horan JK, et al. The cigarette pack as image: new evidence from tobacco industry documents. Tob Control 2002:11:i73-80.

36. Lempert LK, Glantz S. Packaging colour research by tobacco companies: the pack as a product characteristic. Tob Control (in press) doi: 10.1136/tobaccocontrol-2015-052656.

37. Borland R, Savvas S. The effects of variant descriptors on the potential effectiveness of plain packaging. Tob Control 2014;23:58-63.

38. Bansal-Travers M, Hammond D, Smith $\mathrm{P}$, et al. The impact of cigarette pack design, descriptors, and warning labels on risk perception in the U.S. Am J Prev Med 2011;40: 674-82.

39. Scollo M, Bayly M, Wakefield M. Plain packaging: a logical progression for tobacco control in one of the world's 'darkest markets'. Tob Control 2015;24:ii3-8.

40. Brose LS, Chong CB, Aspinall E, et al. Effects of standardised cigarette packaging on craving, motivation to stop and perceptions of cigarettes and packs. Psychol Health 2014;29:849-60.

41. Piqueras-Fiszman B, Spence C. Sensory expectations based on product-extrinsic food cues: an interdisciplinary review of the empirical evidence and theoretical accounts. Food Qual Prefer 2015;40:165-79.

42. Australian Bureau of Statistics. Technical paper: Socio-Economic Indexes for Areas (SEIFA) 2011. Canberra, Australia: Australian Bureau of Statistics, 2013.

43. Heatherton TF, Kozlowski LT, Frecker RC, et al. Measuring the Heaviness of Smoking: using self-reported time to the first cigarette of the day and number of cigarettes smoked per day. $\mathrm{Br} J$ Addict 1989;84:791-800

44. Prochaska JO, DiClemente CC. Stages and processes of self-change of smoking: toward an integrative model of change. $J$ Consult Clin Psychol 1983;51:390-5.

45. Borland R, Balmford J. Understanding how mass media campaigns impact on smokers. Tob Control 2003;12:ii45-52. 
46. Philip Morris. Consumer tracking study: Philippines, 28 December 1988: Tobacco Industry Gateway Documents. Bates: 2504007423 2504007477. http://legacy.library.ucsf.edu (accessed 1 May 2012)

47. Analytic Insight Inc. The smoker's experience: spontaneous language -a qualitative study. Prepared for Brown \& Williamson Tobacco Corporation, 1987.

48. Scollo M, Occleston J, Bayly M, et al. Tobacco product developments coinciding with the implementation of plain packaging in Australia. Tob Control 2015;24:e116-22.

49. Hoek J, Gendall P, Eckert C, et al. Effects of brand variants on smokers' choice behaviours and risk perceptions. Tob Control 2016;25:160-5.

50. International Centre for Settlement of Investment Disputes. Philip Morris Brands and Oriental Republic of Uruguay: ICSID Case No. ARB/10/7, Decision on Jurisdiction, 2013. www.tobaccocontrollaws. org/litigation/decisions/uy-20130702-philip-morris-brands-v.-urugua (accessed 24 Oct 2016)

51. Greenland SJ. The Australian experience following plain packaging the impact on tobacco branding. Addiction 2016;111:2248-58.

52. Greenland SJ, Johnson L, Seifi S. Tobacco manufacturer brand strategy following plain packaging in Australia: implications for social responsibility and policy. Social Responsibility Journal 2016;12:321-34.

53. Tobacco Plain Packaging Act 2011. Australia: Commonwealth of Australia, 2011. http://www.comlaw.gov.au/Details/C2013C00190
54. Scheffels J. A difference that makes a difference: young adult smokers' accounts of cigarette brands and package design. Tob Control 2008;17:118-22.

55. Brennan E, Durkin S, Coomber K, et al. Are quitting-related cognitions and behaviours predicted by proximal responses to plain packaging with larger health warnings? Findings from a national cohort study with Australian adult smokers. Tob Control 2015;24: ii33-41.

56. Chapman S, Byrne F, Carter SM. "Australia is one of the darkest markets in the world": the global importance of Australian tobacco control. Tob Control 2003;12:iii1-3.

57. Moodie C, Bauld L, Ford A, et al. Young women smokers' response to using plain cigarette packaging: qualitative findings from a naturalistic study. BMC Public Health 2014; $14: 812$.

58. Wakefield M, Zacher M, Scollo M, et al. Brand placement on price boards after tobacco display bans: a point-of-sale audit in Melbourne, Australia. Tob Control 2012;21:589-92.

59. Burton S, Hoek J, Nesbit $P$, et al. "Smoking is bad, it's not cool...yet I'm still doing it": cues for tobacco consumption in a 'dark' market. J Bus Res 2015;68:2067-74.

60. Burton S, Williams K, Fry R, et al. Marketing cigarettes when all else is unavailable: evidence of discounting in price-sensitive neighbourhoods. Tob Control 2014;23:e24-9. 